\title{
An integrated approach for wind fields assessment in coastal areas, based on bioindicators, CFD modeling, and observations
}

\author{
Bruno M. Meneses ${ }^{1}$ (D) - António Lopes ${ }^{2}$
}

Received: 16 March 2015 / Accepted: 14 December 2015 /Published online: 29 December 2015

(C) Springer-Verlag Wien 2015

\begin{abstract}
Wind-deformed trees can be good bioindicators of the mean wind speed and prevailing wind directions. The current research used bioindicators, computational fluid dynamics (CFD), and linear models to assess the wind fields in the windy coastal area of Cascais/Portugal. The main objectives of this research are to assess mean speed and directions of winds by using bioindicators and modeling techniques and to correlate both results in order to assess the best methods. The results obtained with the bioindicators showed that carpeting, the most severe deformation, was observed near the shoreline showing that the highest wind speeds are felt in this sector. Inland, where the winds have lower mean speeds, flagging forms are more frequent. When correlated with the bioindicators, the linear model gave better results than CFD models. We can conclude that in areas with good wind potential, the use of bioindicators can be a good alternative in the absence of wind data.
\end{abstract}

\section{Introduction}

The wind affects directly the development of phenological phases and plant growing, especially the development of the

Bruno M. Meneses

bmeneses@campus.ul.pt

1 Institute of Geography and Spatial Planning, Center of Geographical Studies (RISKam Research Group), Universidade de Lisboa. Ed. IGOT, Rua Branca Edmée Marques, 1600-276 Lisbon, Portugal

2 Institute of Geography and Spatial Planning, Center of Geographical Studies (ZEPHYRUS/Climate Change and Environmental Systems Research Group), Universidade de Lisboa. Ed. IGOT, Rua Branca Edmée Marques, 1600-276 Lisbon, Portugal trees that grow near windy coastal areas. Growing season prevailing winds disturb the normal growth of the windward young shoots and do not permit the buds to survive. This is due to the wind mechanical and physiological actions, as well as to the impact of particulate sea salt (Alcoforado 1984). The main impacts are seen in modification dissymmetric shape and dimension of the trees and shrubs. Most damages occur within approximately $300 \mathrm{~m}$ of the ocean, although during strong meteorological events, salt spray damage has been reported on plants $80 \mathrm{~km}$ away from the Atlantic Ocean (Appleton et al. 1999). Therefore, tree deformations by wind can be good indicators of the intensity and persistence of coastal winds and can be used to estimate local wind patterns, especially where a suitable meteorological network is unavailable (Yoshino 1973; Alcoforado 1984; Gipe 2004). There is a long tradition in local climatology involving the use of bioindicators (Alcoforado 1984), and several indices have been used to assess the potential of wind power. Typically, a 2- to 3-year period of hourly anemometric data (wind speed, direction, and turbulence) is needed to assess the wind power and thus the feasibility of a wind farm. However, sometimes, the benefits of the wind power can be overpriced by the time needed to collect data. Therefore, the methods that use bioindicators (e.g., orientation of the trees canopy and degree of deformation), based on a field survey, can be valuable to assess prevailing wind conditions and suitability for the installation of small wind turbines in coastal areas and mountainous terrain (Gipe 2004; Manwell et al. 2009; Mattio and Ponce 1998; Lopes et al. 2010). The most common indices that have been used are Griggs-Putnam index for conifers (Putnam 1948), Barsch index for hardwoods deformation ratio (Barsch 1963), Weischet index (Weischet 1951), and Yoshino index (Yoshino 1973). Alcoforado (1984)produced an adaptation of the Yoshino/Barsch index and, for the first time, applied it to the Cascais coastal region (Portugal). The 
scale of the deformation was adjusted to several Pinus (Pinus pinaster, Pinus pinea, and Pinus halepensis). Where pine trees were absent, eucalyptus (Eucaliptus globulus), olive trees (Olea europaea), "zambujeiros" (local name of $O$. europaea var. sylvestris), poplars (Populus alba), sycamores (Platanus orientalis), ash (Fraxinus angustifolia), cork oaks (Quercus suber), and shrubs (some as tall as trees) like Juniperus turninata subsp. turbinata and Juniperus angustifolia were used as wind indicators. A large number of species with the same degree of wind deformation is a reliable indicator of good quality information for wind assessment (Wooldridge et al. 1992; Gipe 2004), although different species can have different sensibilities to the wind.

\section{Study area and wind regimes}

The western most part of the Lisbon's peninsula is dominated by a medium altitude mountain (Serra de Sintra, Fig.1) that reaches $528 \mathrm{~m}$ (Cruz Alta). To the south of the Sintra Mountain, a littoral platform is slightly pending to the south. Several north/south orientated valleys drain the regional atmospheric fluxes, acting as sources of fresh air that reach the main urban areas.

The area is occupied by several land use/cover types, namely forests (in the Serra de Sintra); sand dunes (in the west, between Raso Cape and Guincho); open fields with short grasslands; urban areas (mostly low to medium dense classes), such as Cascais, Parede, and Carcavelos located in the southern shore; and other human settlements, like the Tires aerodrome and the Estoril race track complex. A total of 5111.5 ha of the Cascais municipal area is occupied by artificial surfaces $(52.4 \%), 3466$ ha of which are urban areas $(67.8 \%)$ with a population of 206,479 inhabitants (2011 census). Tourism is the main economic activity of the region, and Cascais with its beautiful bay, marina, and beaches offers very diverse touristic attractions; in fact, this area has been, for a long time, considered the Portuguese Riviera. Between the Guincho and Carcavelos beaches, in the western and the southern shoreline, several nautical activities (wind surf, kite surf, and sailing) that attract a large number of domestic and foreign enthusiasts depend largely on the wind potential (Vermeersch and Alcoforado 2013).

The north and northwest winds prevail in the study area, although there is a great seasonal variability: N, NW, and NE strongly dominate in spring and summer months, whereas winds from the west, SW, E, and NE are frequent in the colder months of the year (Alcoforado et al. 2006; Lopes et al. 2010; Lopes and Correia 2012).

The summer wind regime is known as Nortada (the north wind). The Nortada is the result of the frequent strong pressure gradient between the Atlantic anticyclone and the low pressure over the Iberian Peninsula (normally with a thermal origin) (Alcoforado et al. 2006). This system and the Nortada intensity can be reinforced by the West Iberian upwelling system. Alcoforado (1987) refers wind gusts with speeds of $75 \mathrm{~km} / \mathrm{h}$ (about $20.8 \mathrm{~m} / \mathrm{s}$ ) registered at the Lisbon Airport during summer and gusts up to $96 \mathrm{~km} / \mathrm{h}$ near the Guincho beach (Alcoforado, 1984).
Fig. 1 Location and topography of the study area, with the localization of the bioindicators/ deformed trees
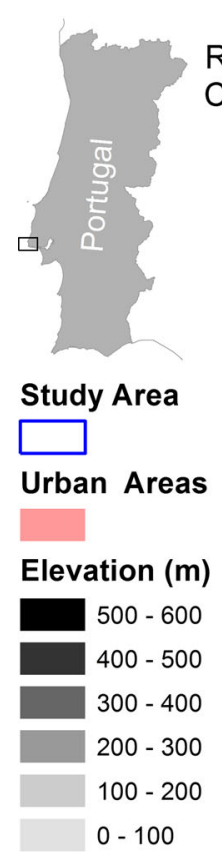

Municipal Boundary

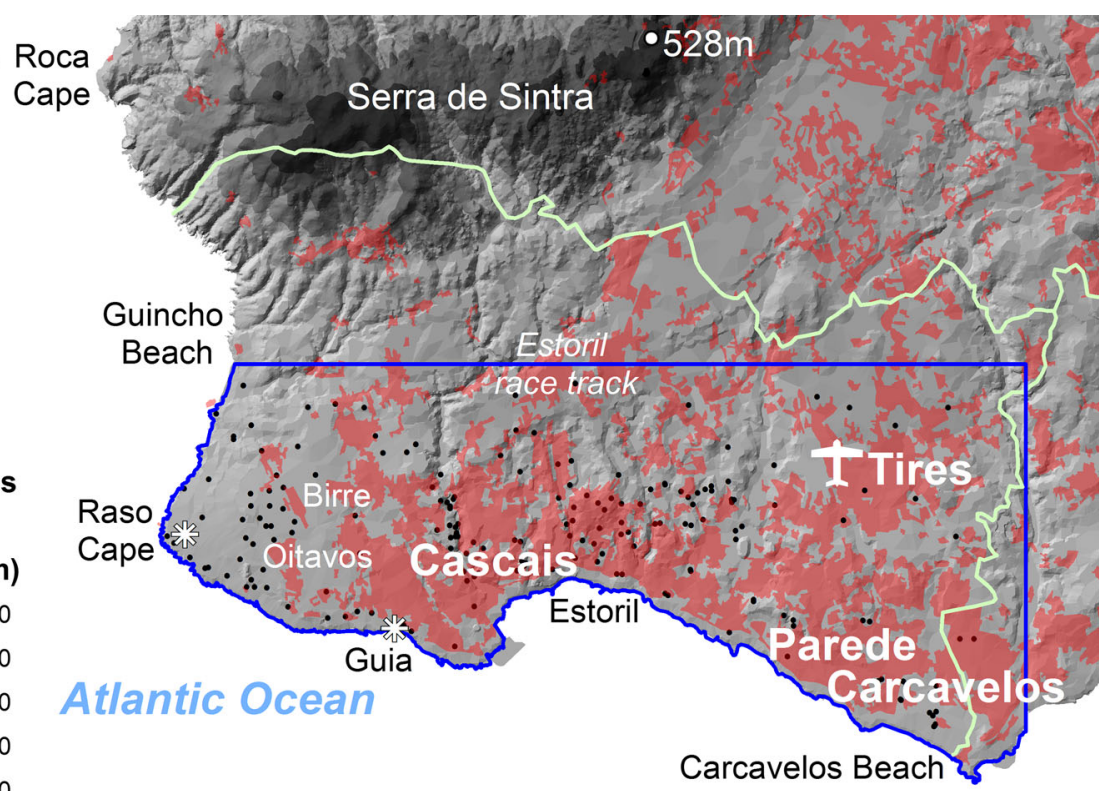

Bioindicators Meteorological stations

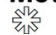

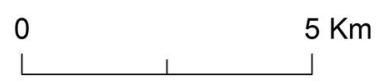




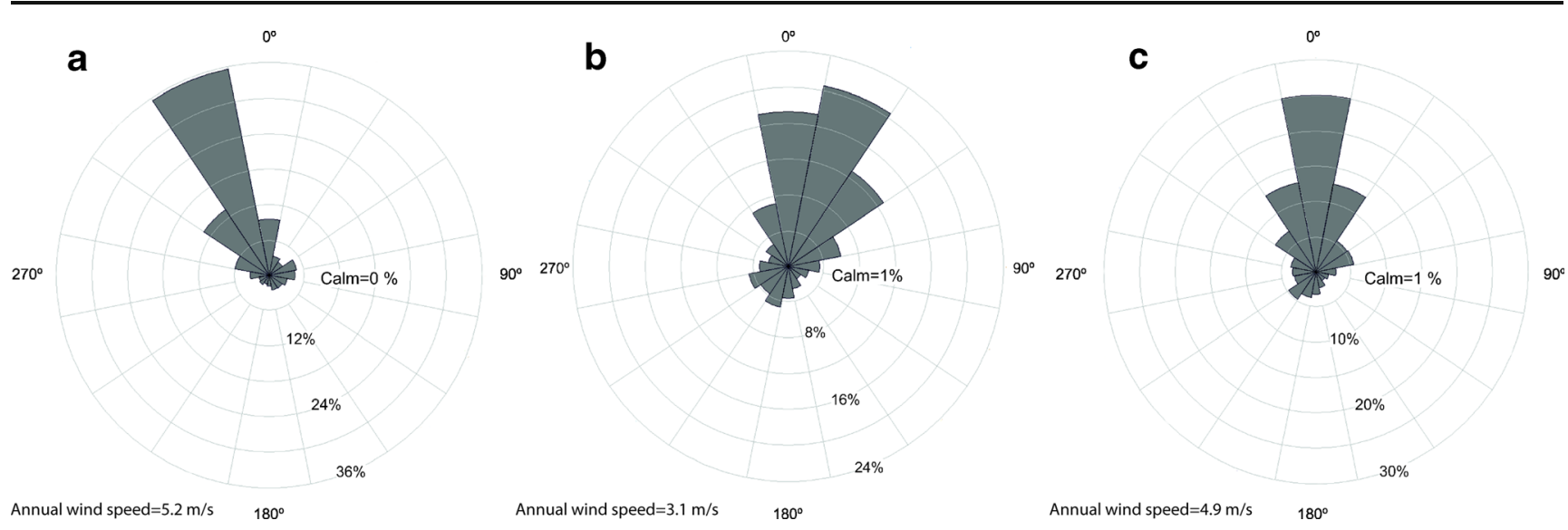

Fig. 2 Wind roses (2008-2011) in the study area: a Raso Cape, b Guia, and c Tires Municipal Airport

In the present study, three meteorological stations of Cascais region were used: the first is located in the central part of the Cascais platform (Tires), the second near the western shore line (Raso Cape), and the third one in the south coast (Guia). Four years of hourly data (2008-2011) are plotted in Fig. 2.

Although, winds from NW, N, and NE are the most frequent in the three stations and the windy characteristic of the study area is corroborated by the small frequency of calm situations $(<1 \%$ in the three meteorological stations).The wind roses reflect also the influence of the Sintra Mountain in the wind direction measured in each station: in Raso Cape, on the western coast (Fig.1), the wind comes mainly from the NW, due to the deflection of the northern flow by the Serra de Sintra, a few kilometers upwind (Alcoforado 1984) and the configuration of the shore line. In Tires, the north wind is prevalent, partly circulating along the eastern edge of the Sintra Mountain, whereas the south shore (Guia station) is sheltered by the upwind relief and in some sites by dense construction: the mean annual wind speed is lower here $(3.1 \mathrm{~m} / \mathrm{s})$ than in the other two stations (Tires $4.9 \mathrm{~m} / \mathrm{s}$ and Raso Cape $5.2 \mathrm{~m} / \mathrm{s}$ ). These two stations register the maximum wind speeds in summer from June to August (Fig. 3), the period when the Nortada is more frequent.

In the western part of the study area, the vegetation is composed mainly by $J$. turninata subsp. turbinata (a species that lives near the sea) and pine trees. Near the shoreline, where the wind is always strong and persistent, the trees are short and strongly wind-deformed, as their trunks and canopies grow alongside the ground indicating "carpeting" (Fig. 4).

The degree of tree deformation by wind is less severe towards the interior (in the eastern part of the region) where flagging forms are very frequent in groups of $P$. pinaster, $P$. pinea, and $P$. halepensis. Other species named above were also used as wind indicators, when pine trees were absent, although their "behavior" to wind is different than Juniperus and pines (Alcoforado 1984).

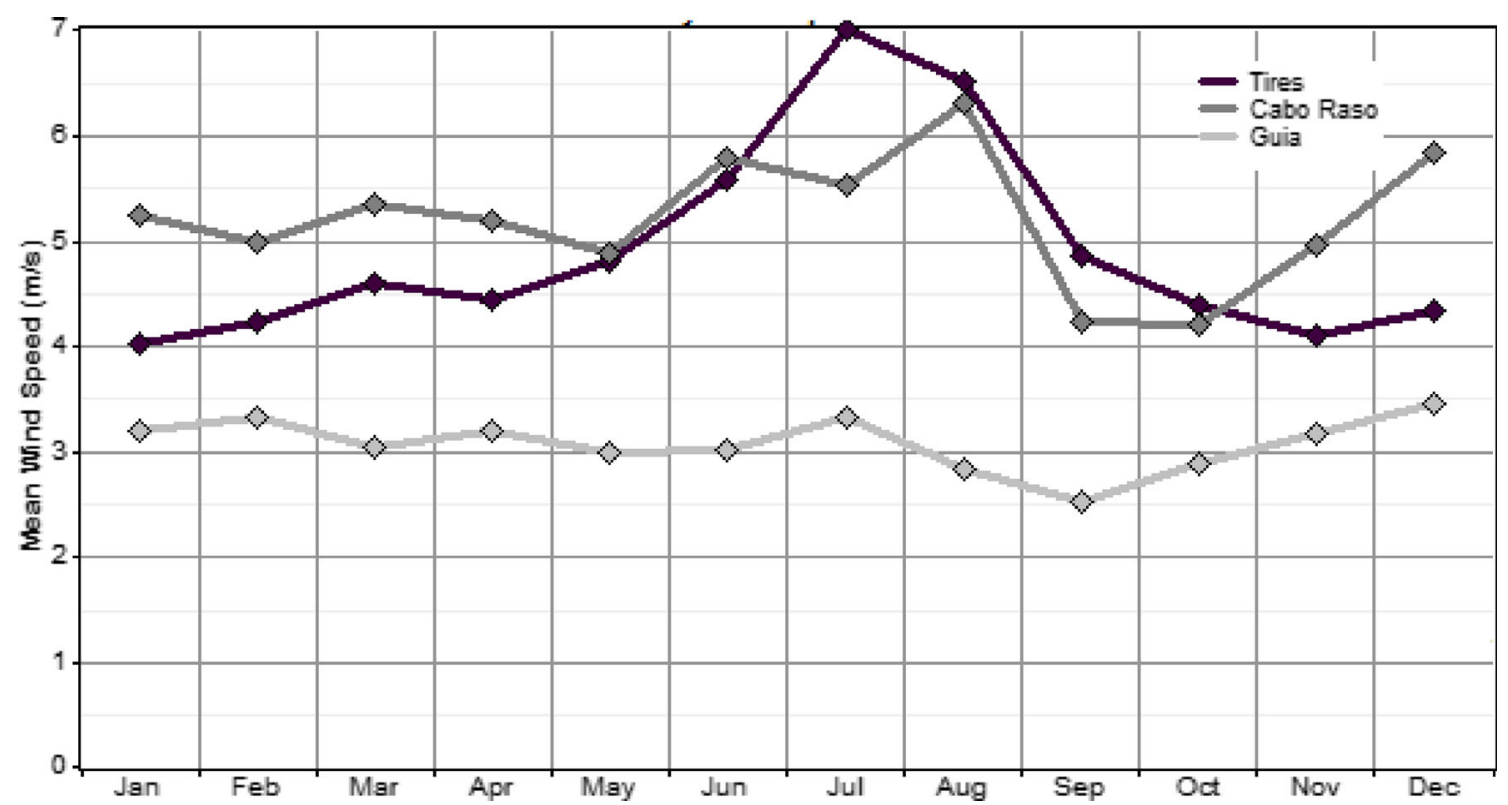

Fig. 3 Monthly wind speed (2008-2011) in the study area (same meteorological stations as in Fig. 2) 


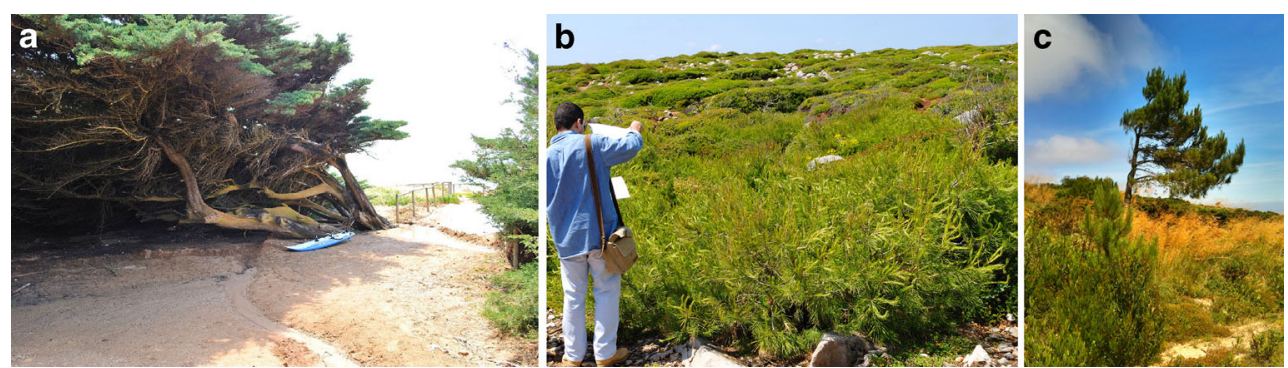

Fig. 4 Wind-deformed trees in the western part of the Cascais platform: a Juniperus trees with "throwing" form, near Guincho beach; b Pinus trees "carpeting" in the foreground near the ocean in Guincho (trunks grow

Windmills are a common feature in the study area and date back to the Arab rule in the region. In Mucana, a poet who lived in Alcabideche/Cascais in the XI century, was known for his poems on this subject, which proves the secular use of wind. According to Lopes and Correia (2012), the region has a good wind power potential with an annual average of about $100 \mathrm{Wm}^{-2}$ and a maximum of about 400 to $500 \mathrm{Wm}^{-2}$ in the northern hills and on the west coast. Although there are a few private small wind turbines (Lopes et al. 2010), the installation of large wind farms is not allowed in most of the region due to its negative visual impact on the landscape and to the restrictions imposed by the Natural Park Sintra/Cascais. Nevertheless, small wind turbines can be set up near the urban areas to produce energy, used by local communities (Cascais Master Plan).

\section{Main objectives}

The main objectives of the present study are (i) to assess wind fields (speed and directions) by using bioindicators (Griggs and Putnam deformation index) and modeling techniques (CFD - computational fluid dynamics and linear models: WAsP-wind atlas analysis and application program, estimated at $10 \mathrm{~m}$ high) in an area that has few meteorological stations; (ii) to evaluate the best method to assess wind characteristics in the absence of measured data; and (iii) to demonstrate the usability of this method in other coastal areas, where the trees can be used as bioindicators. These techniques can be seen as complementary and, in the absence of meteorological stations, will lead to better wind power assessment.

\section{Materials and methods}

\subsection{Tree deformation by wind as bioindicators of wind speed and prevailing direction estimation}

Wind-deformed trees are considered to be good bioindicators for the estimation of the wind fields (speed and prevailing parallel to the ground); c "flagging" Pinus tree in the western part of the study area (near Tires)

directions). It is assumed that dissymmetrical deformations are caused by the wind, by the physiological and mechanical effects, and other meaningless factors, like hereditary, genetics, etc. In this research, tree deformation assessment was based on the Griggs and Putnam index, first established by Putnam in 1948. One of its last revisions (Manwell et al. 2009) uses eight classes of deformation (from 0 to VII) for coniferous trees. Based on Griggs and Putnam's methodology, Wade and Hewson (1979) proposed a methodological approach based on the observation of the trees from the top- and sideview photos (Fig. 5). This methodology allowed us to identify the degree of deformity of the trees in the survey.

The method allows the calculation of a deformation index (DI) according to the typology of the trees (spherical or conical) (Fig. 6). Mattio and Ponce (1998) expanded the concept to globose canopies allowing a complete assessment of tree deformations.

Several measurements are needed for the assessment of the DI: (i) in trees with conical canopy, $\alpha$ and $\beta$ represent the angles formed between the trunk and the extremities of the upwind and downwind canopy, respectively, and $\gamma$ the angle formed by the deflection of the trunk (Wade and Hewson 1979); and (ii) in the trees with spherical canopy (globose), $\mathrm{A}$ and $\mathrm{B}$ represent the distance (in meter) to downwind and upwind top, respectively, in relation to the $Z$ axis, and the angle between $Z$ and the downwind canopy edge $(G)$ (Mattio and Ponce 1998).

In the study area of Cascais, 178 trees (171 with spherical canopy and 7 conic) were photographed and georeferenced in a database. Each photograph (Fig. 7) was carefully checked, and several parameters were obtained from laboratory and field work such as the scientific and the common name, the location (latitude $\lambda$, longitude $\varphi$, and altitude $h$ ), canopy form, trunk and canopy orientation, tree size and several further parameters (A, B, G, $\alpha, \beta$, and $\gamma$-see Fig. 6) and the trunk diameter at breast height (DBH). The DI was computed from the data collected, and a correspondent mean wind speed was assigned. Only isolated trees or trees on the edge of the woodland were chosen for the wind survey because they show a higher degree of deformation as the woodland acts like a protection barrier to the 
Fig. 5 Griggs and Putnam index, type of tree deformation, and correspondent annual mean wind speed (adapted from Hewson et al. (1979) and Manwell et al. (2009))

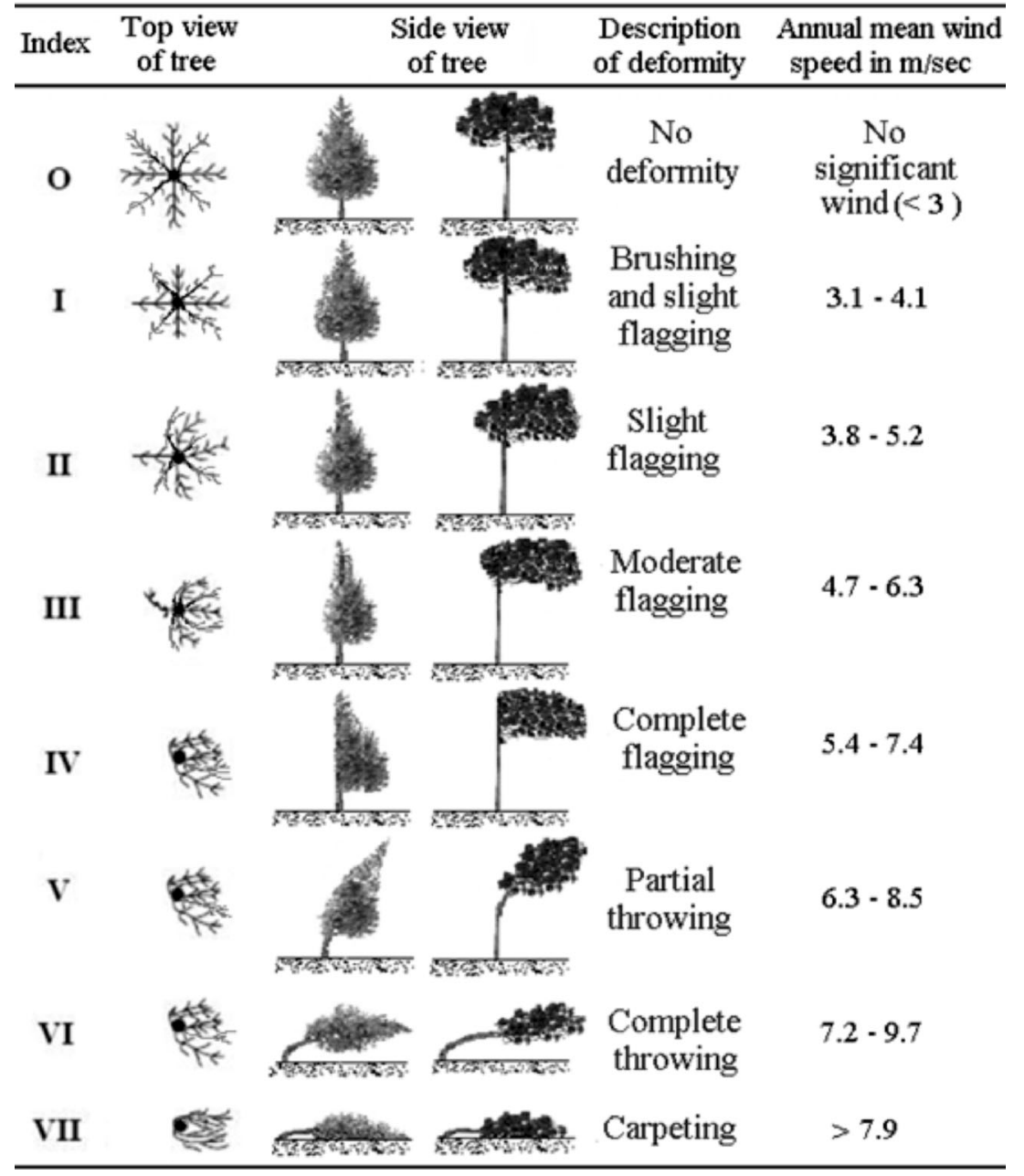

downwind trees. On the other hand, wind turbulence can occur in the sheltered sector, interfering with the normal growth of vegetal species, and special care must be taken during the survey stage (Wegley et al. 1980). Figure 7 shows the various parameters measured in a pine tree $(P$. pinea). The computations were obtained following to the methodologies described by (Wade and Hewson 1979) and (Mattio and Ponce 1998). According to the authors, the differences between globose and conic trees were also taken into account because different species respond differently to the wind.

The majority of the specimens $(96 \%)$ in the database are globose (spherical canopy shape) and only $4 \%$ are coniferous (conic shape), which is a good comparison indicator for the
Fig. 6 Parameters needed to determine the deformation index (DI), according to Wade and Hewson (1979) and Mattio and Ponce (1998) (see more explanations in the text)

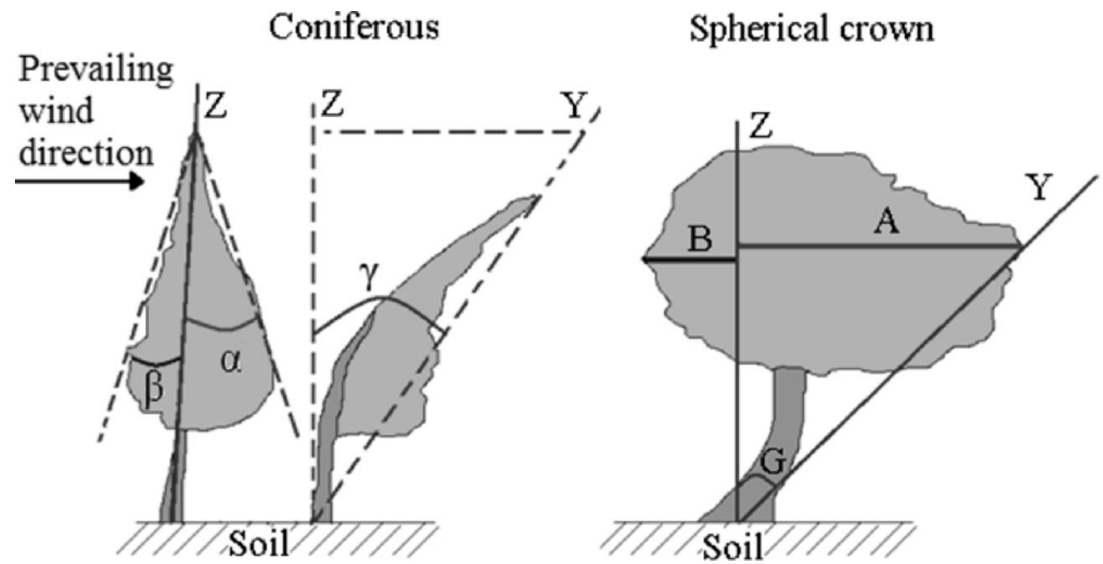




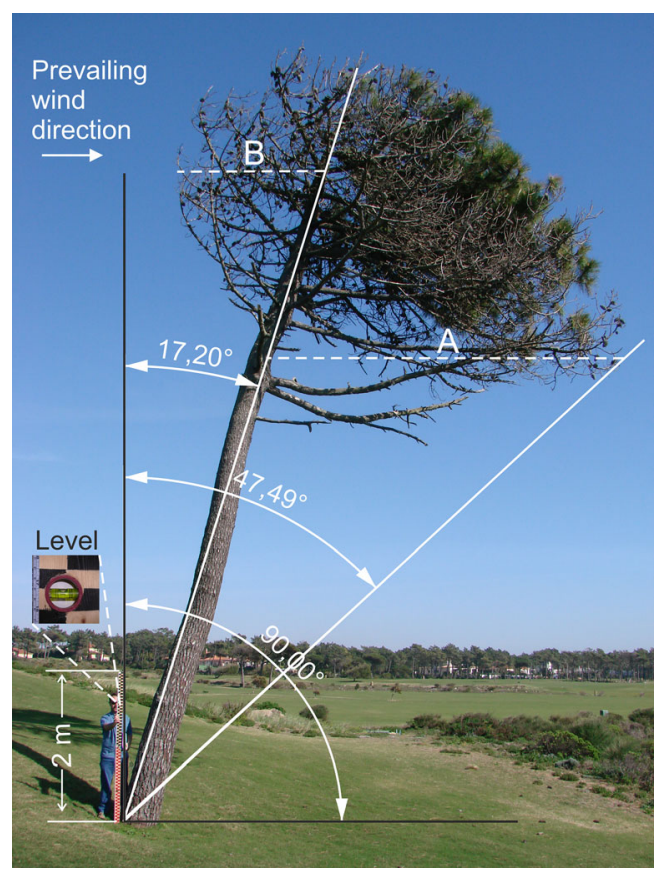

Fig. 7 Measuring the angles and distances of the crown of a winddeformed pine tree located in Cascais (Guia). $A$ and $B$ represents the distances $(\mathrm{m})$ to downwind and upwind top, respectively, in relation to the vertical axis $(\mathrm{Z})$

whole area. Finally, the deformation index of conifers (1) was obtained with the equation proposed by Hewson et al. (1979):

$\mathrm{DI}=\alpha / \beta+\gamma / 45^{\circ} \quad[1 \leq \alpha / \beta \leq 5]$

where $\alpha$ is the angle between the trunk and downwind edge of the canopy, $\beta$ is the angle between the trunk and the end the canopy edge upwind, and $\gamma$ is the angle of deflection of the trunk, considering the downwind edge of the canopy.

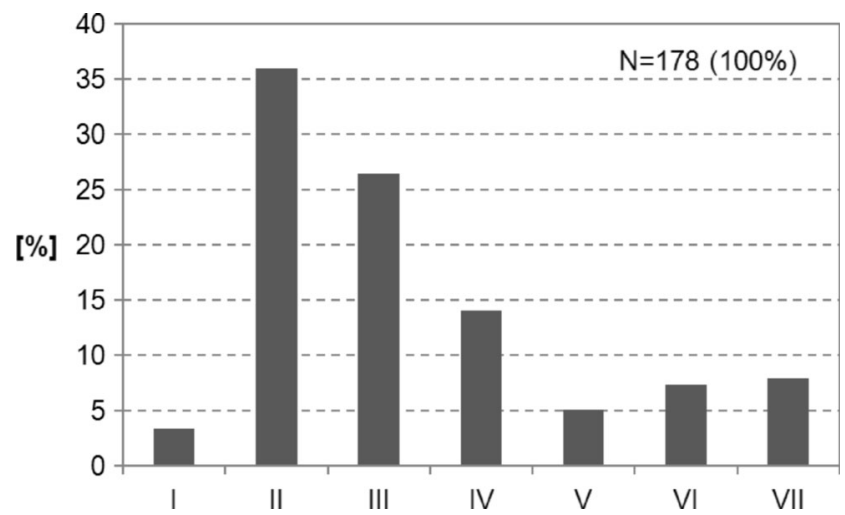

Fig. 9 Frequencies of wind speed classes of Griggs and Putnam index obtained from tree deformation. The relationship between the index and the wind speeds is shown in Fig. 5

The deformation index for trees with spherical canopy was calculated using the following equation: (Mattio and Ponce 1998)

$\mathrm{DI}=\mathrm{A} / \mathrm{B}+\mathrm{G} / 45^{\circ}$

where $A$ and $B$ are the distances (m) between the $\mathrm{Z}$ axis and the downwind and upwind ends of the canopy, respectively, and $G$ is the angle between the $\mathrm{Y}$ axis (alignment between the trunk on the ground and the top of the downwind canopy) and the $\mathrm{Z}$ axis.

Finally, the annual average wind speed at $10 \mathrm{~m}$ high was estimated from the DI and the linear regression models used by Mattio and Ponce (1998). Equations 3 and 4 were used for the different tree groups.

Cypress $\vec{V}=4.05+1.30 \mathrm{DI}(\mathrm{rms}$ Error $=0.40 \mathrm{~m} / \mathrm{s})$

Pine $\vec{V}=3.13+1.64 \mathrm{DI}(\mathrm{rms}$ Error $= \pm 0.34 \mathrm{~m} / \mathrm{s})$

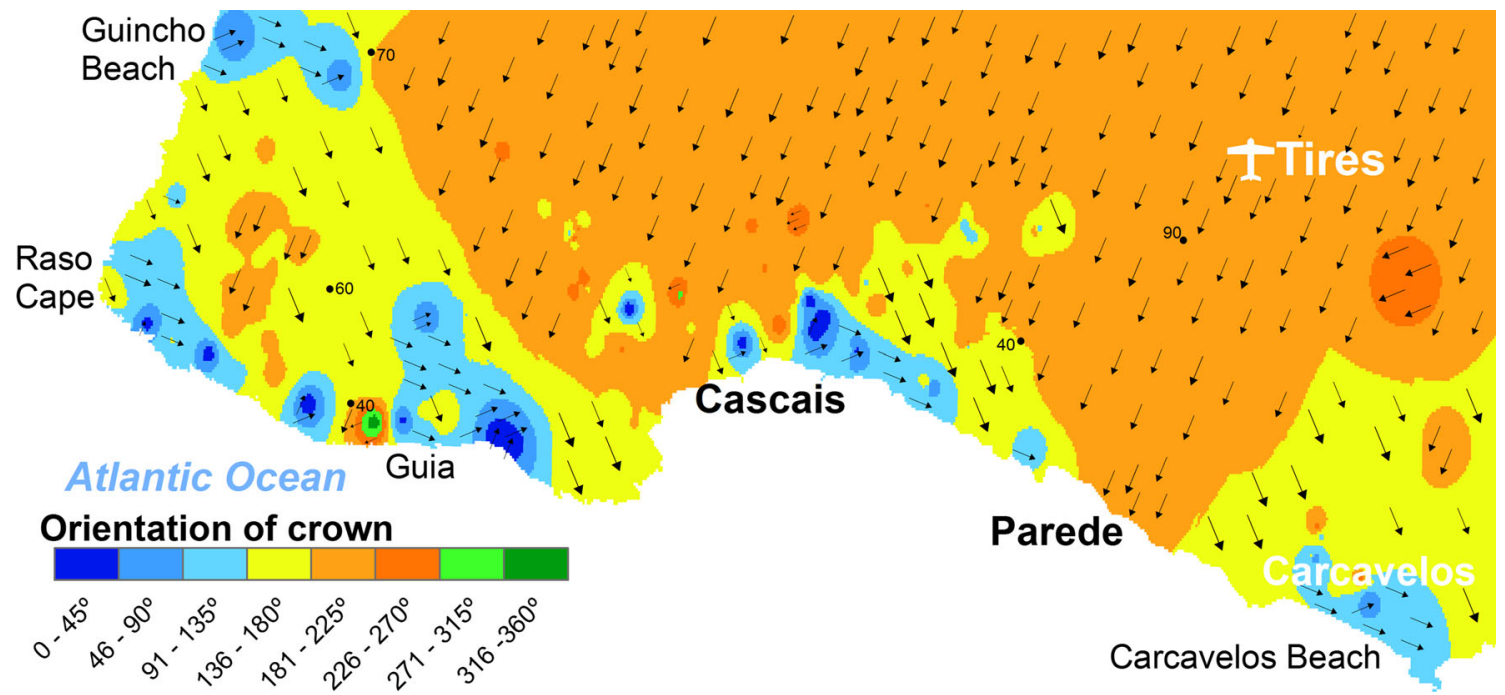

Fig. 8 Prevailing wind direction inferred from tree deformations 


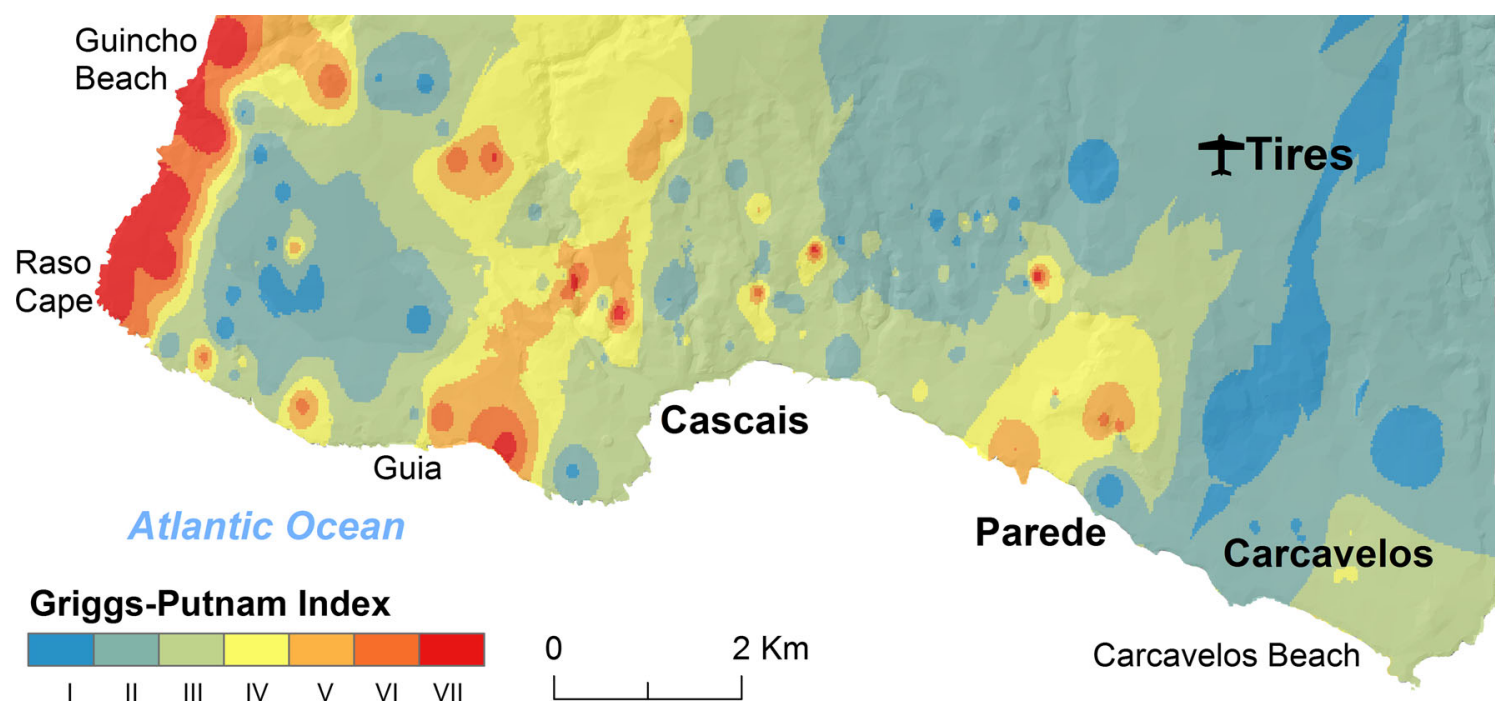

Fig. 10 Distribution of wind speed classes according to the tree deformation. The relationship between the index and the wind speed is shown in Fig. 5

In Eqs. 3 and 4, $\overrightarrow{\mathrm{V}}$ represents the annual average wind speed $(\mathrm{m} / \mathrm{s})$ and DI represents the deformation index.

The final map was made using the following data and technique: for each tree, an "annual mean wind speed" was estimated and a dominant direction was assigned based on the tree deformation; further to this data, latitude $\lambda$ and longitude $\varphi$ (x, $\mathrm{y}$ coordinates) were inserted in a geographical information system (GIS) and the inverse distance weighting (IDW) was used to interpolate the centroids of the grid (pixel $10 \times 10 \mathrm{~m}$ ). This deterministic method is suitable for smooth interpolations, where no disturbances at this mesoscale are expected (Li and Heap 2014).

\subsection{Numerical modeling}

CFD (Windstation 4.0) and linear modeling (WAsP 10) was used to estimate annual wind speed in the area. The Windstation software (Lopes 2003) is a tool for the simulation of wind flow over complex terrain that solves the 3D NavierStokes equations, including turbulence and thermal effects and uses a boundary-fitted coordinate system. Turbulence is simulated with the $k$-e model. Topography and roughness data can enter as an ASCII grid file (Lopes 2003).

WAsP 10 is a state of the art linearized model that predicts wind climates, wind resources, and power production (Troen 1990). The software includes a complex terrain flow model, a roughness change model, and a sheltering obstacles module.

Two layers were used within this work: (i) a digital elevation model (DEM) obtained from the Advanced Spaceborne Thermal Emission and Reflection Radiometer (ASTER), an Earth-observing optical instrument operated by National Aeronautics and Space Administration (NASA, USA) and Ministry of Economy, Trade, and Industry (METI of Japan) from which the Global DEM version 2 (with a spatial resolution of $30 \mathrm{~m}$ ) is produced; (ii) the roughness length $\left(\mathrm{z}_{0}\right)$ was originally obtained from the Portuguese COS 2007 (Carta da Ocupação do Solo-land use/cover map). Each class was assigned a value of $\left(\mathrm{z}_{0}\right)$, according to typical values published in the European Wind Atlas (Troen and Petersen 1989; Stull 2000).

The wind speed and direction data used to assess annual wind fields was obtained from the observations at the Tires Aerodrome meteorological station (Fig. 1). Although we have three meteorological stations in the area, Tires was chosen because it provides a better representation of the wind flows and is less influenced by oceanic and sea breezes (Fig. 2).

Both models ran the same wind data (hourly values from 2008 to 2011) in order that the results can be compared.

WAsP produces a wind atlas data from the original wind meteorological dataset, and the program estimates the expected wind climate at any specific point (Mortensen et al. 2011). The analysis of the Tires Aerodrome meteorological station raw wind data returns annual wind rose, Weibull distribution parameters, and the annual mean wind speed.

In order to compare the results of the bioindicators with linear and CFD models, the prevailing direction (north) and the annual mean speed $(6.5 \mathrm{~m} / \mathrm{s})$ were used as initial conditions on the CFD software (Windstation). The boundary

Table 1 Wind speed $(\mathrm{m} / \mathrm{s})$ estimated by the bioindicators, the linear model/WAsP and the CFD/Windstation (pixel $10 \times 10 \mathrm{~m}$ )

\begin{tabular}{llll}
\hline & Bioindicators & WAsP & CFD \\
\hline Mean & 4.8 & 4.1 & 3.6 \\
Standard deviation & 0.46 & 0.60 & 0.37 \\
Max. & 6.5 & 6.0 & 4.8 \\
Min. & 4.1 & 2.7 & 2.8 \\
\hline
\end{tabular}




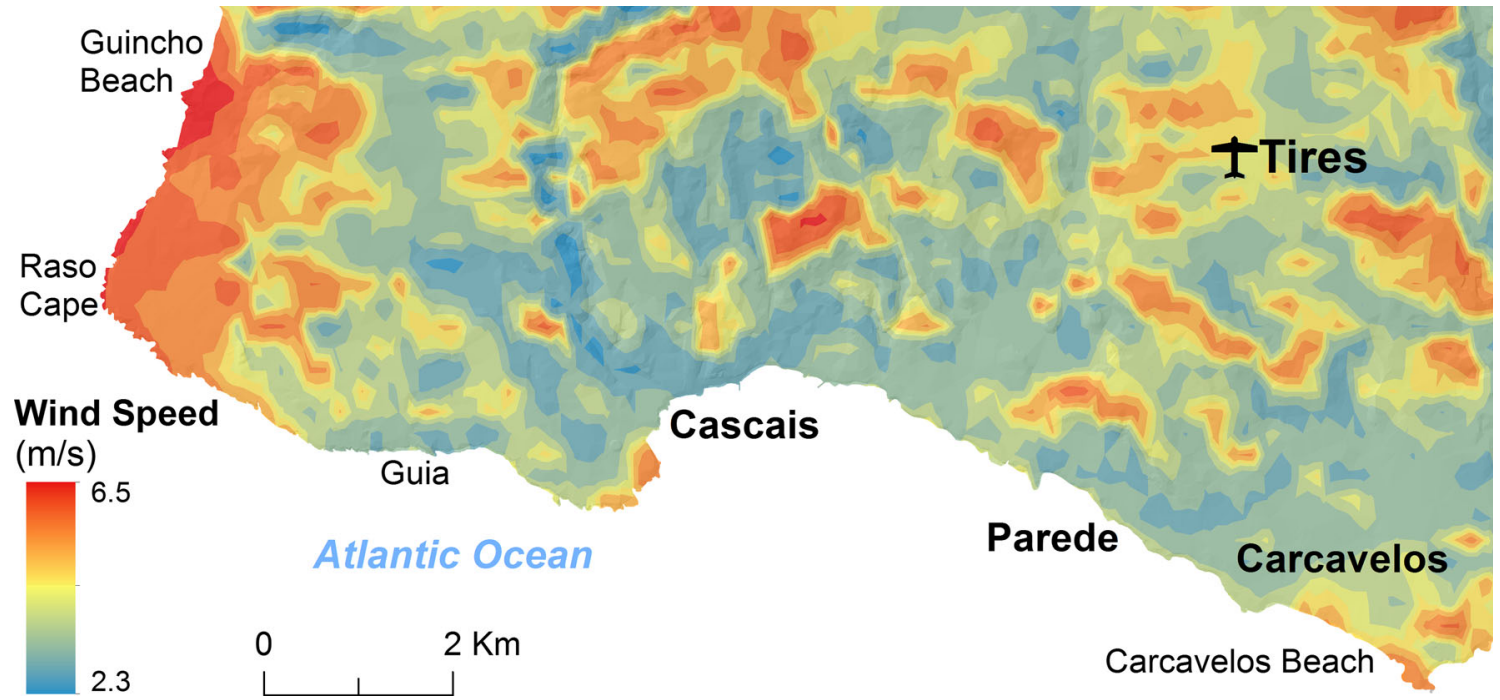

Fig. 11 Wind speed obtained from WAsP linear model

conditions were set to neutral atmosphere stability, the same condition used by WAsP. The results of the tree deformation were compared with CFD and linear modeling by means of linear regressions, whose point were the 178 surveyed trees.

\section{Results and discussion}

\subsection{Prevailing wind direction and wind speed obtained from tree canopy deformations}

As can be seen in Fig. 8, the N and NE are the prevailing wind directions in the study area, although in the western sector, between Raso Cape and Guincho Beach (see Fig.1), and in the southeastern sector, the wind blows from NW, as confirmed by Alcoforado (1984).
The local convergent areas observed in the field (shown in Fig. 8) are due to the 500-m Serra de Sintra (Fig.1) that acts as a barrier and modifies the regional atmospheric flows around it. Wind divergence can occur in the contact areas with different aerodynamic roughness, namely between the edges of urban areas and open spaces (Oke 1987).

The majority of the tree deformation fall into classes II and III of the Griggs and Putnam index (Fig. 9), indicating annual average wind speed between 3.8 and $6.3 \mathrm{~m} / \mathrm{s}$, especially in the Birre/Oitavos area (see Fig. 1 for location) and in the northeast part of the study area (Fig.10). Here, the aerodynamic roughness is lower due to the absence of forests and dense urban areas. In the western areas, more exposed to ocean winds, the carpeting forms are dominant indicating average wind speeds greater than $7 \mathrm{~m} / \mathrm{s}$ (index, VI and VII). Tree deformations of classes III and IV (26.4 and $14.0 \%$, respectively) are also observed along the bottom of the valleys as a result of the

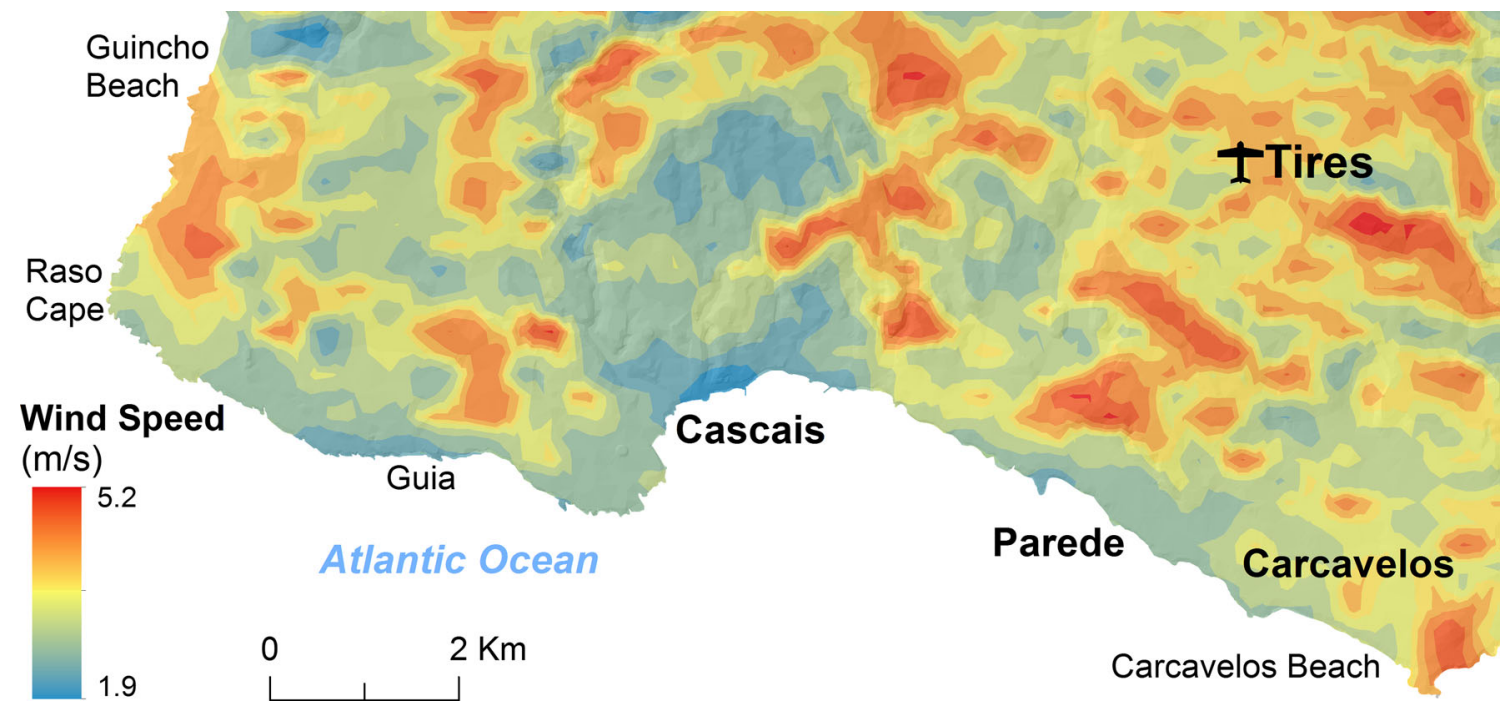

Fig. 12 Wind speed obtained from CFD model 

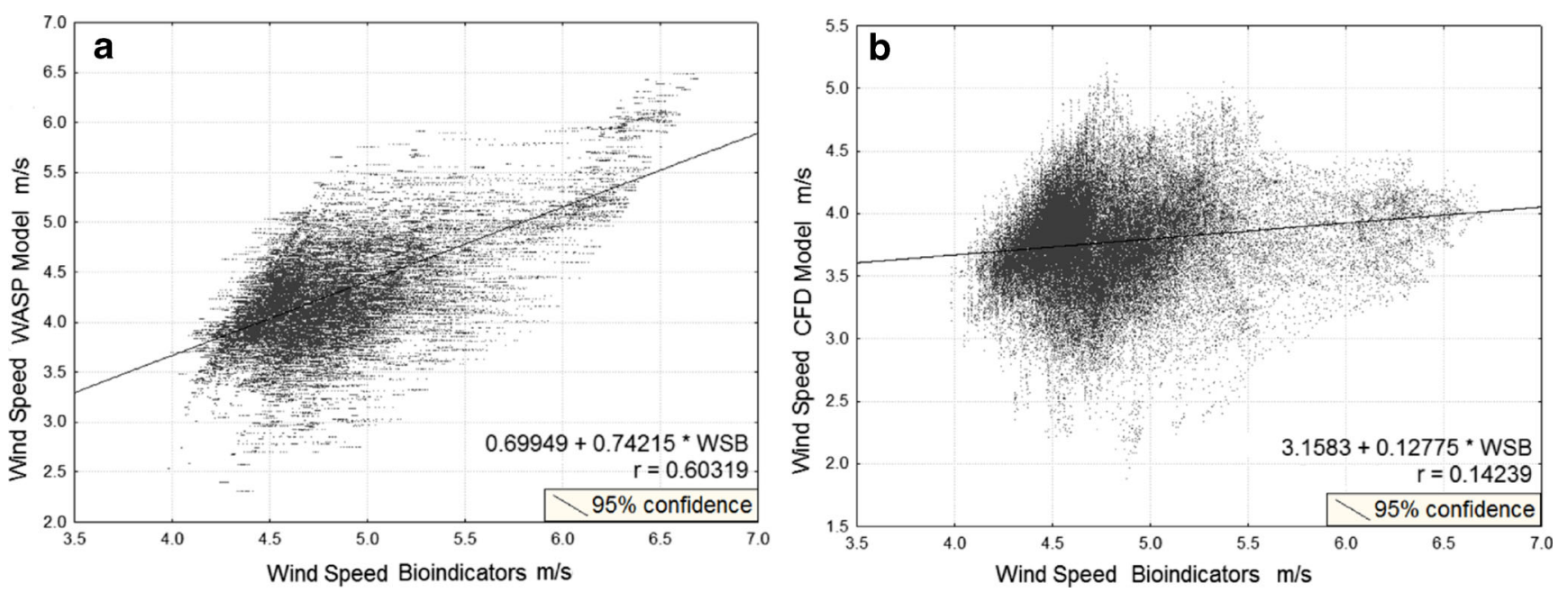

Fig. 13 Mean wind speeds correlation between bioindicators and WAsP (a) and bioindicators and the CFD model (b)

channeling effect. Local wind acceleration can therefore be confirmed by tree deformations and orientations.

Along the southern shore, between Raso Cape and Carcavelos, the tree canopies lean towards $\mathrm{E}$ and NE indicating a prevailing $\mathrm{SW}$ wind direction. This can be explained by the deflection effect of the prevailing N and NW flow caused by the relief and its possible re-entrance inland blowing from the SW on a narrow strip of the littoral platform.

\subsection{Wind speed obtained with linear modeling and CFD}

In order to compare wind speeds computed by the two numerical models (WAsP and CFD/Windstation) and the bioindicators, three layers of information were created (each one with a grid resolution of $10 \times 10 \mathrm{~m}$ ). The basic statistics of each layer are presented in Table 1. As can be seen, the CFD outputs have the lowest values, whereas WAsP yields values that are closer to the bioindicators, therefore, more realistic.

WAsP software produced very smooth interpolation in the region as can be seen in Fig. 11. The mean wind speed in all the computed area was around $4.1 \mathrm{~m} / \mathrm{s}$, with a standard deviation of $0.6 \mathrm{~m} / \mathrm{s}$. The windiest areas are located in the western part of the region, near the ocean, with annual mean speed greater than $6 \mathrm{~m} / \mathrm{s}$, which is coincident with the results obtained with the tree deformation assessment (Fig. 10). In natural non-occupied hills and crests, with lower roughness lengths $\left(\mathrm{z}_{0}\right)$, values greater than $5 \mathrm{~m} / \mathrm{s}$ were estimated. Due to the fact that WAsP uses simplified models that do not take into account the non-linear effects to estimate the horizontal wind speed, some areas present dissimilarities of tree deformation, especially in the valley beds, where the estimated wind speeds are lower than expected $(<3 \mathrm{~m} / \mathrm{s})$.

The CFD model outputs are shown in Fig. 12. The mean wind speed obtained with this model is about $3.6 \mathrm{~m} / \mathrm{s}$, with a maximum of $4.8 \mathrm{~m} / \mathrm{s}$ and a minimum of $2.8 \mathrm{~m} / \mathrm{s}$. The areas with higher altitude are the ones with the highest wind speeds, especially Serra de Sintra. The lowest wind speeds occur mainly in the sheltered areas of the prevailing $\mathrm{N}$ wind. The advantage of this method over the linear model is that it can better reproduce wind speeds in wake zone in the south of the hills and crests.

The correlations between the three techniques are presented in Fig. 13. The wind speeds obtained with the CFD is less correlated with the bioindicators $(0.14$ - for a $95 \%$ confidence interval) than WAsP which has an $r=0.60$.

\section{Conclusions}

Tree deformations, CFD, and linear models are different methods to estimate wind flows. Each one of these methods has its own specificities: wind assessment using bioindicators (namely tree deformations) is more time consuming because it requires expensive field and laboratory work. But it has the advantage to allow the evaluation of atmospheric flow conditions in areas where the information from meteorological stations is absent or scarce, especially in areas where the wind is constant all year long. A linear model is not as robust technique as CFD, but requires less computational time than the latter. The major limitations are related with wind speed accuracy in wake zones (i.e., leeward of hills and mountainous terrains) where higher wind speeds occur and with its restriction to smooth hills where flow separation is not to be expected (Lopes 2003). With regard to the wind power estimation, the method has, however, some advantages in representing long-term data. CFD is generally more computational time consuming for complex terrain and has better spatial resolution. Furthermore, some available methods do not provide a complete simulation of the wind fluxes, but they are quite effective in predicting recirculation effects and thermal stratification (Lopes 2003). However, it is not suitable to represent long-term data, but instead initial conditions for a prognostic 
situation, even for future conditions as those predicted by climate change studies.

Comparing with the observations registered in the newly available meteorological stations, the bioindicators yield good results in the estimation of the wind speed and prevailing direction in the Cascais coastal area. The results we obtained showed that the more severe tree deformations were observed near the shoreline, revealing the greatest wind speed in this sector derived from the higher speeds over the ocean surface. The bioindicators also revealed higher wind speeds in the valleys is explained by the channeling effect caused by these landforms.

The modeling of the wind speed with WAsP and CFD models shows the $10-\mathrm{m}$ height wind speed prevailing from $\mathrm{NW}$, differentiating the coastal areas (W and NW) with the highest wind speeds from the interior with less intense winds. The results obtained by WAsP model present greater correlation with those obtained by bioindicators, so this model has the best performance of the two computational methods used in this study.

The three methodologies used to interpolate the mean wind speed showed very similar qualitative results, especially near the shoreline and in the hill tops. However, the estimated bioindicator values show some differences from the results with WAsP and CFD models especially in the areas that can be influenced by sea breezes or are located in valley bottoms and, therefore, are more realistic. In future research, it is our intention to analyze the differences between the methods in several topographic forms and positions.

It was clearly demonstrated that the assessment of the areas with the highest wind potential using simplified methodologies, such as the use of bioindicators, can be a good alternative in areas with no available wind data.

Acknowledgments The authors would like to thank Prof. Dr. Maria João Alcoforado and the anonymous reviewers that contributed to the improvement of this paper. We are also thankful to Luís Miguel Faria for his help in the fieldwork.

\section{References}

Alcoforado MJ (1984) Representação Cartográfica das árvores deformadas: ventos dominantes em torno da Serra de Sintra. Finisterra 19:137-169

Alcoforado MJ (1987) Brisas estivais do Tejo e do oceano na região de Lisboa. Finisterra 22:71-112

Alcoforado MJ, Andrade H, Lopes A, Vasconcelos J, Vieira R (2006) Observational studies on summer winds in Lisbon (Portugal) and their influence on daytime regional and urban thermal patterns. Merhavim 6:90-112
Appleton B, Huff R, French S (1999) Evaluating trees for saltwater spray tolerance for ocean front sites. J Arboric 25:205-210

Barsch D (1963) Wind, Baumform und Landschaft. Freiburg Geogr Hefte $1: 21-130$

Gipe P (2004) Wind power: renewable energy for home, farm, and business. Chelsea Green Publishing, Vermont

Hewson EW, Wade JE, Baker RW (1979) A handbook on the use of trees as an indicator of wind power potential. Final Report, Oregon State University

Li J, Heap AD (2014) Spatial interpolation methods applied in the environmental sciences: a review. Environ Model Softw 53:173-189

Lopes A, Correia E (2012) A proposal to enhance urban climate maps with the assessment of the wind power potential. The case of Cascais Municipality (Portugal). In: Kožnarová V, Sulovská S, Hájková L (eds) Bioclimatology of Ecosystems. International Scientific Conference. Ústí nad Labem, Czezh Republic, pp 68-69

Lopes A, Fragoso M, Meneses BM, Madeira J, Faria LM, Reuter M (2010) Methodologies to the assessment of wind power in Cascais region. In: Figueiredo T, Frölen-Ribeiro L, Castro-Ribeiro A (eds) II workshop climate and natural resources in Portuguese speaking countries (in Portuguese) (peer reviewed abstracts). IPB, Bragança, pp. 297-305

Lopes AG (2003) WindStation - a software for the simulation of atmospheric flows over complex topography. Environ Model Softw 18: $81-96$

Manwell J, McGowan J, Rogers A (2009) Wind energy explained: theory, design and application, 2nd edn. Wiley. Retrieved from google books

Mattio HF, Ponce GA (1998) Estimación de la velocidad media anual del viento en función de indicadores biológicos. Nociones Generales de Energía Eólica. Argentina, In, pp. 159-167

Mortensen NG, Heathfield DN, Rathmann O, Nielsen M (2011) Wind atlas analysis and application program: WAsP 10 Help Facility. Ris $\varnothing$ National Laboratory for Sustainable Energy. Technical University of Denmark, Roskilde, Denmark 356 topics

Oke T (1987) Boundary layer climates. Routledge

Putnam PC (1948) Power from the wind. Van Qostrand Co. Inc, New York, p. 224

Stull RB (2000) Meteorology for scientists and engineers, 2nd edn. Brooks/Cole Thomson Learning, Pacific Grove

Troen I (1990) A high resolution spectral model for flow in complex terrain. In: Ninth Symposium on Turbulence and Diffusion. Roskilde, pp 417-420

Troen I, Petersen EL (1989) European wind atlas. Risø National Laboratory, Roskilde

Vermeersch W, Alcoforado MJ (2013) Wind as a resource for summer nautical recreation. Guincho Beach Study Case Finisterra 45: $105-122$

Wade JE, Hewson EW (1979) Trees as a local climatic wind indicator. J Appl Meteorol 18:1182-1187

Wegley HL, Ramsdell JV, Orgill MM, Drake RL (1980) A siting handbook for small wind energy conversion systems. Windbooks. Washigton, USA, pp. 297-305

Weischet W (1951) Die Baumneigung als Hilfsmittel zur geographischen Bestimmung der klimatischen Windverhältnisse: (Dargestellt am Beispiel der Köln-Bonner Bucht). Erdkunde 5:221-227

Wooldridge G, Musselman R, Conner B, Fox D (1992) Airflow patterns in a small subalpine basin. Theor Appl Climatol 45:37-41

Yoshino MM (1973) Studies of wind-shaped trees: their classification, distribution and significance as a climatic indicator. Climatological Notes 12. Toyko, Japan 